\title{
Effectiveness of Disney's NLP-based Strategy to Improve Student's Higher Order Thinking Skills
}

\author{
Mohamad Tahar Mohamad Amirnudin \\ Kolej Matrikulasi Perak, Gopeng, Perak, Malaysia,rahatvirtual@gmail.com
}

\section{Salmiza Saleh}

Asst. Prof., Faculty of Educational Studies, Universiti Sains Malaysia, Penang, Malaysia, salmiza@usm.my

Neuro Linguistic Programming (NLP) is person-excellence research as it explores the most effective behavioural process to achieve personal quality. The method incorporates either oral or non-verbal interaction to influence the human mind's system to quickly and effectively change behaviour. Such type of communication will change the experience stored in the human mind and modify the expected feelings, ideas, and actions. This present research is, therefore, aimed at exploring the feasibility of Disney's NLP-based strategy to improve students' higher-order thinking skills (HOTS). This study employed a pre-test / post-test quasiexperimental design involving 40 participant-students from a Malaysian matriculation college. The researchers used an intact group technique to determine the sample and divided the participants into two groups, namely the control group using conventional modules, and the experimental group using Disney's NLPbased Strategy. Instruments used are Disney's NLP-based Strategy and a HOTS test. The instrument used to obtain HOTS data was a subjective test in which the indicators were based on Bloom's Revised Taxonomy. The results from the data analysis represented the efficacy of Disney's NLP-based Strategy application on the students' HOTS. The findings of this study have shown that Disney's NLPbased approach can be used as a means to facilitate college lecturers in matriculation in nurturing competent students.

Keywords: mathematics education, NLP, higher order thinking, disney strategy, revised bloom taxonomy, neuro linguistic programming, Malaysian matriculation college

\section{INTRODUCTION}

The education system's primary purpose is to equip every student with the knowledge and skills to be successful in life. Therefore, through courses such as science, mathematics, and literature, the Malaysian education system has focused on developing information content. There has been an acknowledgement, though, that

Citation: Amirnudin, M. T. M., \& Saleh, S. (2020). Effectiveness of Disney's NLP-based Strategy to Improve Student's Higher Order Thinking Skills. International Journal of Instruction, 13(3), 293-306. https://doi.org/10.29333/iji.2020.13320a 
content alone is inadequate for learners. Learning evolves not only around gaining knowledge but also developing skills such as higher order thinking skills (HOTS).

HOTS is a cognitive process at the level of analysis, synthesis and assessment in Bloom's Taxonomy, whereas Low Order Thinking Skills (LOTS) is a cognitive process at the level of knowledge, understanding and application (Fisher, 2006; Krathwohl, 2002). HOTS is a cognitive process consisting of critical thinking and creative thinking (Krulik \& Rudnick, 1999; Marzano, 1993) which develops when gained knowledge is applied in the context that ignites the ability to analyse, evaluate, and create, eventually leads to development of skills that can be used to solve new or non-routine problems (King, Goodson, \& Rohani, 1998).

From the historical perspective, the use of HOTS began in the time of Socrates, when the use of critical thinking in philosophy was widespread (Lewis, 2001). HOTS was subsequently utilized by psychologists, who concentrated on the thinking process, with more emphasis on building insight by experience known as problem-solving (Lewis, 2001). Problem-solving is more focused on the process; nevertheless, it requires students to implement critical thinking and creative thinking to solve non-routine problems (Hamza \& Griffith, 2006). Problem-solving will develop the ability of students to analyze, evaluate and create in order to have the critical and innovative thinking skills to solve everyday problems (Polya, 1945; Wallas, 1926; Apino \& Retnawati, 2017).

However, as far as HOTS is concerned, students' current thinking skills are still below par. This is founded on the assessment by Trends In International Mathematics and Science Study (TIMSS), and the Programme for International Student Assessment (PISA); It was found that the application of HOTS remains challenging for students in Malaysia (Mullis, Martin, Foy, \& Hooper, 2014; OECD, 2016). Based on the PISA report, Malaysian students' achievements are significantly below the four grades, with 88.9 per cent of students reported having difficulty applying HOTS (Kementerian Pendidikan Malaysia, 2016). The TIMSS report also showed similar findings in which $75 \%$ of students did not optimally implement HOTS (Ministry of Education, 2016a).

This research, therefore, explored the magnitude of the ability of Disney's NLP-based strategy to improve students' HOTS. It was pillared on research by Beeden (2008) and Bell (2016), which optimistically verified that this approach could improve the students' HOTS.

\section{Disney's NLP-based Strategy}

NLP provides a mechanism to guide one's brain systematically. It teaches people not only to control their state and behaviour but as well as other people's (Bandler, 1985). In brief, it is the science of brain operation that ideally produces desired results through verbal or non-verbal communication with oneself (A. Robbins \& Robins, 1986).

John Grinder and Richard Bandler founded NLP; they are respectively a professor and a psychologist at the University of California in Santa CruzThey initially conducted a study on the factors that enable individuals to excel and replicate the excellence at desired times. They observed people who are exhibiting their behaviour patterns and thinking styles. Bandler and Grinder identified, validated and established a technique 
called NLP (Churches \& West-burnham, 2008). These two geniuses have also made many discoveries, in addition to providing a powerful and efficient collection of formulas to make changes. More specifically, they presented a comprehensive understanding of how it is possible to duplicate individual achievements in a short time.

Throughout NLP, the method of observing aspects of what individuals are doing, how they perceive, feel and behave is called modelling (Churches \& Terry, 2007). With the NLP, the term modelling embodies the fundamental principle; 'If one person can do something, then it is possible to model and teach it to others' (O'Connor, 2001). NLP can explain the process in the mind that causes such behaviour to take place (Dilts, 1994). Today, NLP is used to study the competence and effectiveness of people from all walks of life, across all disciplines and fields, including Walt Disney (Gray, 2008; Seitova et al., 2016).

The grandeur of the animated films produced by Walt Disney was recognized by many viewers (Dilts, 1994). A genius element of Disney was his ability to explore something from a variety of different positions of perception to solve a problem (Storr, Loveday, Kilpatrick, Curran, \& Cooper, 2012). According to Dilts (1996), these Disney ideas are produced through three phases, namely the Creative Phase, Realistic Phase, and Critic Phase. Disney's strategy is a sophisticated form of thought in which Disney often uses three separate modes of thinking. Parallel thinking involves analyzing problems, generating ideas, evaluating ideas, building, and criticizing action plans. Robert Dilts (1994) developed the Disney approach using NLP information known as NLP modelling. To be great at problem-solving, coordination of thought is a priority (Kotera \& Sheffield, 2017).

Disney Strategy's first phase is the Creative Phase. Students are asked to ' visualize ' their creative past success by using the NLP method (Beeden, 2008). This is a method of looking forward to finding new ideas for planning or resolution. The phase includes incorporating creative thinking to create new solutions and alternatives (Dilts, 1998) (Dilts, 1998). According to Brookhart (2010), the Creative Phase is the process of generating ideas. In this step, there are no right or wrong principles, but ideas should be produced as much as possible because they will be revised in the following processes.

Nevertheless, calmness is vital in this process (Wallas, 1926), that the mind must be clear to focus on the problems that need to be addressed. A calm and optimistic attitude will improve thought capacity (Churches \& West-Burnham, 2008). The physiological position and a calm mind, therefore, play a role in making this phase successful (Dilts, 1996). Physiology contributes as much as 55 per cent to help minds taking action, according to Ready and Burton (2010). This proves that proper physiology will grant the mind peace and help it to generate appropriate ideas for problem-solving (Beeden, 2008).

The suitability of the ideas will be tested in the second phase, the Realistic Phase to ensure that they are realistic and rational (Dilts \& Bonissone, 1993). Students were required to' visualize' their Realistic past success (Beeden, 2008). In this phase, execution procedures and means are critical (Dilts, 1996). As the ideas acquired during the Creative Phase are in rough and vague, they will be further developed to be more 
practical and compatible with the current situation (Dilts, 1998). In this phase, the ideas generated will be carried out while the steps are being evaluated, for zero mistake effort (Polya, 1945). Disney will have animated characters to ensure the effective implementation of the ideas. In NLP, it is called the technique of the First Perceptual Position (O'Connor \& Seymour, 1990), which illustrates the decline in the desired situation as if it occurred before the eyes (Bandler, 1985; Churches \& Terry, 2007; Churches \& West-burnham, 2008).

In the final phase, an assessment on ideas will be conducted (Dilts, 1998) utilizing NLP technique called Technique of the Second Perception Position. To determine the strengths or limitations of a concept or model, hence, this approach is believed to be helpful (O'Connor, 2001). There is always room for improvement permitting these phases to be reproduced to perfection, starting with the Creative Phase (Kotera \& Sheffield, 2017). Criticism applies exclusively to ideas or preparation, but not processes (Dilts \& Bonissone, 1993).

1.

Creative

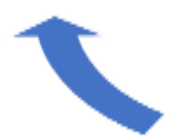

\section{Critic}

Figure 1

Disney's Strategy Cycle

\section{HOTS Element}

Through its implementation, Disney's NLP-based strategy will boost the students' HOTS. Disney's strategy includes three phases, as follows:
1. Creative Phase
2. Realistic Phase
3. Critic Phase

The first phase of Disney's Strategy is the Creative Phase. Students will execute the process of generating new ideas to solve a particular problem in this phase. Students will generate ideas, plan, and produce their ideas at the creation level, which corresponds to Bloom's Revised Taxonomy (Anderson at al., 2001a).

Next, in Realistic Phase, the ideas gained from the Creative Phase will be implemented by students. Students will analyze the implementation of the ideas during this phase. Based on Bloom's Revised Taxonomy, differentiating, organizing and contributing are cognitive processes that may occur (Anderson at al., 2001a).

Finally, the ideas undergo an evaluation process at the Critical Process (Dilts, 1998). The solutions obtained will be reviewed and questioned by students. If an error occurs, students are required to rectify it, and if the answer is incorrect, they can even restart the Creative Phase. 


\section{Aim of the Research}

This study aimed to evaluate the feasibility of Disney's NLP-based strategy to boost students' HOTS based on the framework mentioned above.

\section{METHOD}

\section{Research Design}

This study sought to investigate the effect of Disney's NLP-based Strategy on students' HOTS. The selection of experimental methods utilizing quantitative approaches is, therefore appropriate, especially if the particular study attempts to test the cause-effect relationship (Piaw, 2006; Cook, Campbell, \& Shadish, 2002). A quasi-experiment model was chosen to assess the feasibility of employing Disney's NLP-based strategy. It was supported by Campbell and Stanley (2015), noting that the development of an experimental study was designed specifically to determine the potency of the results of an independent variable in the context of the research.

A two-group pre-test/post-test quasi-experimental design has been adopted for this study. Disney's NLP-based strategy and conventional teaching were the independent variables. The dependent variable was the students' HOTS. Based on the variables involved and the objectives to be achieved, the design used was a non-equivalent pretest and post-test control group design (Creswell, 2014).

This research was conducted on 1,825 students divided into 36 classes at Perak Matriculation College, Malaysia, of the 2018/2019 academic year. Sampling was performed using an intact group technique to determine two sample class groups. F1T3 was the control class which used conventional teaching and F2T3 as the experimental class, which used Disney's NLP-based Strategy). Respectively, 20 students were selected for the control class, and the experimental class, making the total sample count to 40 .

Table 1

Experimental Procedures

\begin{tabular}{ll}
\hline Action & Timeframe \\
\hline Disney's Strategy application Workshop & One day \\
Pre-test and course procedure information & 1 hour \\
Teaching \& Learning Activity & 12 weeks, 2 hours per week \\
Post-test and course procedure information & 1 hour \\
\hline
\end{tabular}

\section{Research Instruments}

The instruments used were modules of Disney's NLP-based Strategy and a HOTS test. The HOTS test was adapted from matriculation test questions and modified according to the elements of the HOTS, which comprises of analysis evaluation and creation. Three mathematics education experts had theoretically validated that the instruments fit the criteria for validity.

Empirically, the reliability of the test had also been assessed on 31 students. All questions were valid, and Cronbach's Alpha value is 0.87 , which is above 0.8, indicating that all items were reliable (George \& Mallery, 2003). 
The following are the items' values of Difficulty Index and Discrimination Index (Macintosh \& Morrisson, 1969):

Table 2

Value Index Difficulty and Item Discrimination Index

\begin{tabular}{|c|c|c|c|c|}
\hline \multicolumn{3}{|c|}{ Number of Items } & Difficulty Index & Discrimination Index \\
\hline \multirow{4}{*}{1} & \multirow{2}{*}{$\mathrm{a}$} & $\mathrm{i}$ & 0.78 & 0.51 \\
\hline & & \multirow[t]{3}{*}{ ii } & 0.69 & 0.63 \\
\hline & $\mathrm{b}$ & & 0.58 & 0.55 \\
\hline & $\mathrm{c}$ & & 0.61 & 0.71 \\
\hline \multirow{3}{*}{2} & \multirow{3}{*}{$\begin{array}{l}\mathrm{a} \\
\mathrm{b}\end{array}$} & & 0.77 & 0.55 \\
\hline & & & 0.66 & 0.69 \\
\hline & & & 0.73 & 0.52 \\
\hline \multirow{6}{*}{3} & \multirow{2}{*}{$\mathrm{a}$} & $\mathrm{i}$ & 0.71 & 0.53 \\
\hline & & ii & 0.63 & 0.64 \\
\hline & \multirow{2}{*}{$\mathrm{b}$} & $\mathrm{i}$ & 0.78 & 0.63 \\
\hline & & ii & 0.71 & 0.71 \\
\hline & $\mathrm{c}$ & & 0.63 & 0.73 \\
\hline & d & & 0.61 & 0.55 \\
\hline \multirow{6}{*}{4} & $\mathrm{a}$ & & 0.74 & 0.51 \\
\hline & $\mathrm{b}$ & & 0.61 & 0.56 \\
\hline & \multirow{3}{*}{$\mathrm{c}$} & $\mathrm{i}$ & 0.65 & 0.61 \\
\hline & & ii & 0.66 & 0.66 \\
\hline & & iii & 0.71 & 0.63 \\
\hline & $\mathrm{d}$ & & 0.77 & 0.64 \\
\hline
\end{tabular}

Module of Disney's NLP-based Strategy

This module was developed using the Sidek and Jamaludin Module Development Model (2005). The model is appropriate because Malaysian norms have been factorized in Sidek's Module Development Model (SMDM). SMDM is a more robust unified model in module development. For each stage, the approach of the model has two sub-stages, with different goals. The first stage is the preparation of a draft module by the developer. This stage has nine steps, beginning with the goals of setting a module and ending with combining activities (intervention) into a complete module. This draft module, however, has not yet been validated, and its reliability has not yet been measured.

The second stage of the SMDM is the assessment of the draft module. At this stage, to ensure validity and reliability, the designed module must be tested in a pilot study. The development of the model is considered complete if it obtained validity and reliability values. The next step involves an expert's analysis in the form of suggestions, comments and descriptive values. The following formula is employed to determine an expert's average value for each indicator:

Content Validity Achievement $=\frac{\text { Total Score }}{\text { Maximum Score }} \times 100 \%$

Sidek Mohd Noah and Jamaludin Ahmad (2005) developed the formula to calculate the expert's content validity (refer to Table 3). The result is represented in percentage (\%). According to Sidek and Jamaludin (2005), if and only if the content validity percentage 
is more than $70 \%$, the content validity of the module is good; vice versa. Should the latter be the case, it is advisable to revise the content according to the study's objective.

The researchers appointed three experts. All of them practised the NLP in their teaching. Therefore, they have respectable, reputable, and unquestionable knowledge and experience.

Table 3

Validation Results

\begin{tabular}{lll}
\hline Experts & Total of Validity Achievement (\%) & Criteria (Valid/Not Valid) \\
\hline Experts 1 & 96 & Valid \\
Experts 2 & 92 & Valid \\
Experts 3 & 96 & Valid \\
\hline Average & 94.67 & \\
\hline
\end{tabular}

Based on Table 3, Expert 1 and Expert 3 (96\%) gave the highest percentage, but Expert 2 gave the lowest percentage (92\%). Disney's NLP-based strategy obtained an average total of $94.67 \%$ in terms of validity index. It can, therefore, be assumed that the module produced is valid and all examiners accept the fact that the module's content is relevant to the activity's objectives.

The researchers then constructed a set of questionnaires centred on the objectives of evaluating the reliability of Disney's NLP-based strategy. As stated by Jamaludin and Sidek (2005), the method for developing items to assess the reliability of the module is dependent on the objectives of its activities. Upon completing the activities, the sample participants answered the questionnaire. The questionnaire's reliability was evaluated using Cronbach's Alpha coefficient. According to Mohd Majid (1990), if the reliability value is high with a minimum value of 0.60 , it means the module has good consistency. On the other hand, if the reliability value is lower than 0.60 , the module has a weak consistency and needs improvement.

Reliability determination was performed on 31 students of Matriculation College who adopted Disney's NLP-based strategy. The questionnaires on the reliability of the module were given to students after each activity in the module had been performed. The questionnaires were analysed for reliability values using Cronbach's Alpha coefficient. For analysis, the researchers used the Statistical Package for Social Sciences version 23 (SPSS); Disney's Strategy Module obtained 0.873 for 33 items. A minimum reliability index value of 0.5 is appropriate for a module's reliability index value, according to Valette (1977). Othman Mohamed (2000) suggested that the reliability index value to consider and accept a newly developed module must be between 0.65 and 0.85 . Although there are many perceptions and recommendations on how to ascertain the reliability index values before a module is implemented, Disney's Strategy Module produced an exceptional value of 0.873 in this research; thus, reliability is acknowledged.

Disney's NLP-based strategy enabled students to participate actively in the learning process by linking new ideas to the cognitive structure (knowledge), which comprises of learning objectives, materials and methods, in addition to instruments or media, as well as learning and evaluation resources. Disney's strategy consists of three phases, i.e. 
Creative, Realistic, and Critic (Dilts, 1994). The students were allowed to generate ideas to solve the problems at the Creative Phase. Students were given the opportunity to generate ideas and create a plan by connecting the information from previously shown lectures (see Table 4). They chose and implemented the most appropriate ideas at the Realistic Phase. They checked the solutions at the Critic Phase and corrected any existing errors. These phases have the potential to improve comprehension, provide opportunities to develop ideas and increase their HOTS.

Table 4

Disney's Strategy Phases

Phases of

Disney's Steps

Strategy

Understand the questions by writing the information obtained from the questions in Disney's strategy Worksheet (see Figure 3).

Place the Anchor Creative Sheet on the table (see Figure 2).

Take a breath and slowly release it - repeat three times.

Sit down and be comfortable

Think of a time when you could creatively imagine a new idea to answer

Creative mathematics questions without judging yourself.

Step onto this paper and relive that experience.

See what you saw, hear what you heard, and feel what you felt.

Repeat until you can see, hear, and feel that moment when you look at the

worksheet - repeat three times, minimum.

Then, propose alternative solutions and write down the planning in the Strategy

section of Disney's Worksheet strategy

Place the Anchor Realist Sheet on the table.

Take a breath and slowly release it-repeat three times.

Recall the situation that you have successfully answered mathematical questions.

How did you confidently implement that idea and plan?

Realistic Imagine that situation on the Anchor Realist Sheet.

Repeat until you can see, hear, and feel that moment when you look at the

worksheet - repeat three times, minimum.

Next, use the Disney Strategy Worksheet to implement the ideas obtained from

the Creative Phase

Place the Anchor Critic Sheet on the table.

Take a breath and slowly release it - repeat three times.

Recall the situation that you have successfully answered mathematical questions. Imagine that situation on the Anchor Critic Sheet.

Critic Recall what you see, hear, and feel at the time.

Repeat until you can see, hear, and feel that moment when you look at the worksheet - repeat three times, minimum.

Please check the solution by using Disney's Strategy Worksheet.

If the solution is wrong, please repeat from the Realistic phase.

The following was Disney's NLP-based Strategy:

International Journal of Instruction, July $2020 \bullet$ Vol.13, No.3 


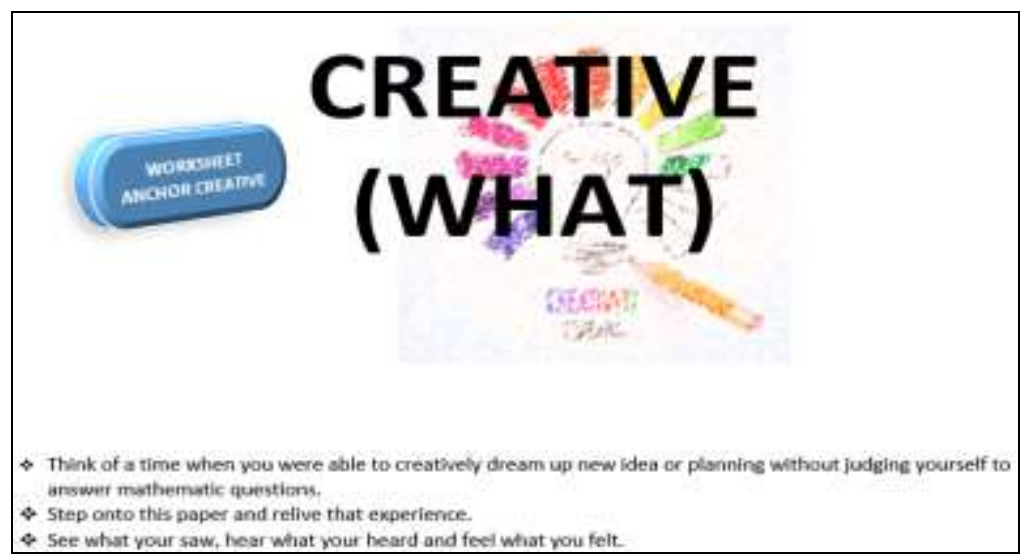

Figure 2

Anchor Creative Sheet

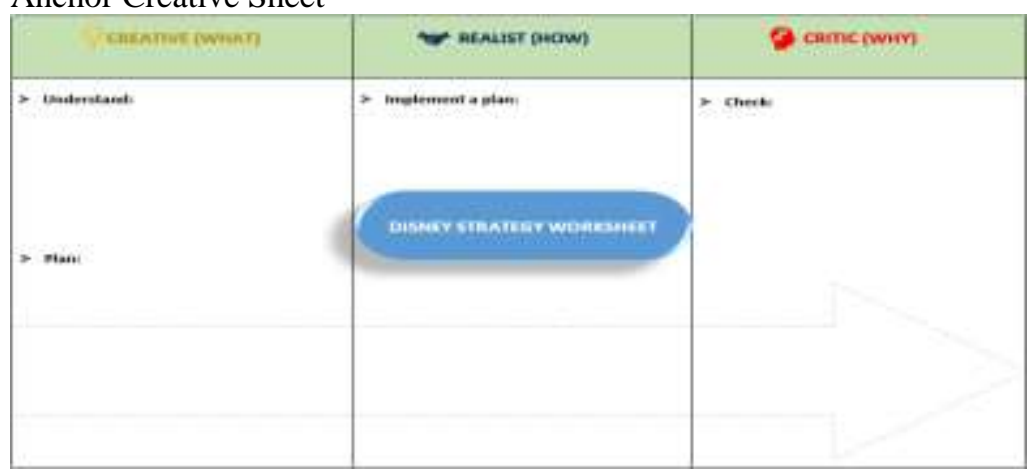

Figure 3

Disney's Strategy Worksheet

\begin{tabular}{|c|c|}
\hline (6) puminat & - es usintes \\
\hline 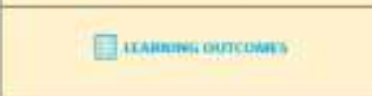 & 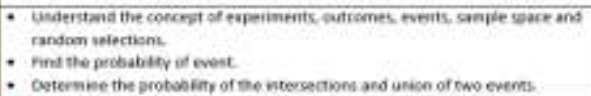 \\
\hline 28 aessrow & 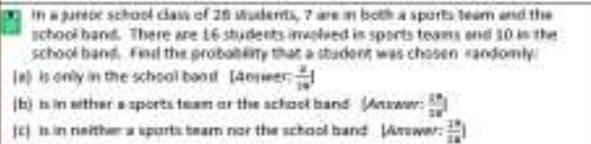 \\
\hline 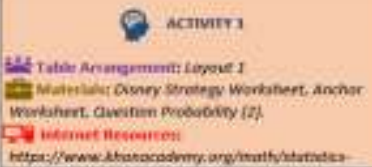 & 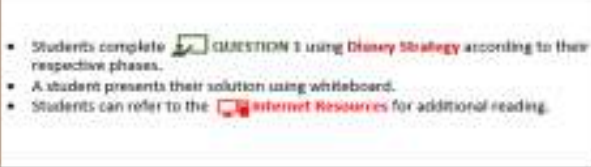 \\
\hline
\end{tabular}

Figure 4

Teaching Guide Using Disney's NLP-Based Strategy

International Journal of Instruction, July $2020 \bullet$ Vol.13, No.3 


\section{Data Analysis Techniques}

The data analysis techniques used an inferential statistical analysis. The inferential statistical analysis was employed to analyze data from the higher-order skills test results. The data were analyzed using an independent t-test sample and a paired t-test sample. Both tests operated SPSS program version 23.

All tests were performed at a significance level of 0.05 to compare the achievement of HOTS in the two groups of students.

\section{FINDINGS}

A paired sample t-test analysis was conducted to determine whether or not the mean pretest and post-test scores in the treatment and the control groups in the HOTS test were significantly different. The results of this study (Table 5) demonstrates that the post-test mean score of the students $(\mathrm{M}=70.65, \mathrm{SD}=12.33)$ is significantly higher in the treatment group $(\mathrm{t}(19)=-10.21, \mathrm{p}<.05)$ than their pre-test mean score $(\mathrm{M}=37.70$, $\mathrm{SD}=11.74)$. Similar results are also found in the control group that the mean post-test score of the students $(M=56.00, S D=9.81)$ is significantly higher than their mean pretest score $(\mathrm{M}=41.10, \mathrm{SD}=7.83)$ in the HOTS. These results indicate that in the post-test, both groups performed significantly better than in the HOTS pre-test. However, the average increase in the mean scores of 32.95 in the treatment group was found to be higher than the average increase in the control group's mean scores of 14.09 .

Table 5

Mean Scores Difference between Pre- and Post-Test of Control and Treatment Groups

\begin{tabular}{lllllll}
\hline Group & Pre-test & Post-test & Difference & t & df & p \\
\hline & & Mean (SD) & & & & \\
Treatment & $37.70(11.74)$ & $70.65(12.33)$ & $-32.95(6.25)$ & -10.21 & 19 & 0.008 \\
Control & $41.10(7.83)$ & $56.00(9.81)$ & $-14.09(4.12)$ & -2.95 & 19 & 0.000 \\
\hline
\end{tabular}

Note: Significant level at $\mathrm{p}=0.05$

An independent-sample t-test was conducted to compare the mean scores of the pre-test in HOTS between the control group and the treatment group. The result of this study (Table 6) indicates that there was no significant difference between the control group and the treatment group in the pre-test mean scores $(\mathrm{t}(38)=1.23, \mathrm{p}=0.225)$. If there is no significant difference between the two pre-test means, according to Gay, Mills, and Airasian (2011), a t-test can be calculated on the post-test means. Consequently, an independent sample t-test was carried out to compare the mean scores of the post-test in HOTS between control and treatment groups. The result of this analysis confirms that students in the treatment group scored significantly higher $(\mathrm{t}(38)=-6.39, \mathrm{p}<0.05)$ than students in the control group $(\mathrm{M}=70.65, \mathrm{SD}=12.33)(\mathrm{M}=56.00, \mathrm{SD}=9.81)$. This finding implies that the mean post-test scores for participants in the control group and the HOTS treatment group are significantly different.

Table 6

Group Difference in Pre-Test and Post-Test Mean Scores

\begin{tabular}{lllllll}
\hline Test & Control & Treatment & Group Difference & t & df & $\mathrm{p}$ \\
\hline & & Mean (SD) & & & \\
Pre & $41.10(7.83)$ & $37.70(11.74)$ & $3.4(2.76)$ & 1.23 & 38 & 0.225 \\
Post & $56.00(9.81)$ & $70.65(12.33)$ & $-14.65(3.38)$ & -6.39 & 38 & 0.000 \\
\hline
\end{tabular}




\section{DISCUSSION}

The results of the t-tests proved that Disney's NLP-based strategy had a significant effect on the HOTS of the students. In the activities involving Disney's strategy, the significant impact was found, in which they could decently accommodate each HOTS indicator. This might boost the HOTS of the students. In other words, students who undergo Disney's NLP-based strategy possess HOTS compared to those who use conventional teaching. This is attributed to the activities in Disney's Strategy that might trigger serious efforts to develop HOTS.

The model-based constructivist theory would trigger the students to perform the activities (Osborne \& Wittrock, 1985). In conventional teaching, on the other hand, there are very few activities; resulting in a lack of involvement during the learning process in building knowledge. IN other words, conventional teaching has a little contribution in promoting knowledge construction for learners (Prayitno, Corebima, Susilo, Zubaidah, \& Ramli, 2017).

Many student activities could empower their thinking process. They may occur in an active process when students build meaningful systems and understand the facts through their experiences and interactions with learning sources and friends (J. K. Robbins, 2011). The results of this study were in line with previous studies that revealed that Disney's strategy might encourage students to develop their HOTS (Bell, 2016).

Students are responsible for helping those with disabilities to grasp the subject matter through Disney's strategy, providing positive relationships with their peers, and being actively involved in the learning process. In Disney's strategy, the activities they do together help them understand the subject matter promptly.

When it comes to developing students' HOTS, the learning process implemented using Disney's approach is more beneficial. Additionally, HOTS requires thinking, analyzing, evaluating and developing activities (Paul \& Elder, 2013; Widiawati, Joyoatmojo, \& Sudiyanto, 2018). It is, therefore, appropriate to discuss problems using Disney's Strategy to encourage students to improve their HOTS.

Disney's strategy was implemented by exploring a problem when the learning process takes place (Alrahlah, 2016; Chen \& Chang, 2014). Students may be encouraged to apply HOTS when encountering with a problem (Gholami at al., 2016; Şendağ \& Odabaş1, 2009). When solving problems, students must understand the materials in the first place, followed by analysis, evaluation, and creation of solutions on the subject matter or problems.

The Anchor Sheet (Figure 2) helped students access every thinking mode in this study. This reflects results from previous studies in which different thoughts were generated by the anchor (Kotera \& Sheffield, 2017; Beeden, 2008; Bell, 2016). This is the only justification that this work was exceptional in contrast to previous studies. Rooms were used as an anchor for most previous studies. The Guide Sheet may have helped students to think critically and feel optimistic that increase self-esteem and selfefficacy. Thus, the connection between these subjects should be discussed in future studies. 


\section{CONCLUSION}

Based on the results of the research, it is concluded that the application of Disney's NLP-based Strategy has effectively improved the HOTS of students. The efficacy was indicated by the t-test result specifically a value of sig. (2-tailed) of $<0.05$. Students can develop their HOTS when they by actively engaging in problem-solving discussion activities at the beginning of the learning process.

Applying Disney's approach to solve a problem involves multiple tasks such as analyzing, evaluating, and creating as these practices are aligned with HOTS indicators As a consequence, it takes quite a long time to implement Disney's NLP-based strategy. This was observed in the situation in which, due to time constraints, instructors can only allow two groups to present their work.

\section{RECOMMENDATIONS}

It is recommended to all parties who would implement Disney's NLP-based strategy to pay extra attention when considering the needed time to enact the learning procedures. $\mathrm{Be}$ vigilant with time is essential to manage and implement learning procedures successfully. Implementing Disney's NLP-based strategy is time-consuming; thus, developing a convincing and compelling plan for this process is imperative. In fact, the ability of educators to implement Disney's approach relies on their HOTS, accurately observing and setting for specific themes. Only if the educators could comprehend a challenge from a different point of view, then HOTS be achieved. This would become the future directions for research.

\section{REFERENCES}

Apino, E., \& Retnawati, H. (2017). Developing instructional design to improve mathematical higher order thinking skills of students. Journal of Physics: Conference Series (Vol. 812, p. 12100). IOP Publishing.

Bandler, R. (1985). Using your brain for a change. (S. Andreas \& C. Andreas, Eds.). Real People Press.

Bell, L. L. (2016). Neuro-linguistic programming in the classroom: The disney strategy. Elementary Teacher's Federation of Ontario (ETFO), 30-45.

Brookhart, S. M. (2010). How to assess higher-order thinking skills in your classroom. ASCD.

Churches, R., \& Terry, R. (2007). NLP for teachers: How to be a highly effective teacher. Crown House Publishing.

Churches, R., \& West-burnham, J. (2008). Leading learning through relationships : the implications of Neuro-linguistic programming for personalisation and the children' $s$ agenda in England. CfBT Education Trust.

Cook, T. D., Campbell, D. T., \& Shadish, W. (2002). Experimental and quasiexperimental designs for generalized causal inference. Houghton Mifflin Boston.

Creswell, J. W. (2014). Research design: Qualitative, quantitative, and mixed methods 
approaches. Sage publications.

Intergovernmental Panel on Climate Change. (2014). Summary for policymakers. In Climate change 2013 - the physical science basis: Working group I contribution to the fifth assessment report of the intergovernmental panel on climate change (pp. 1-30). Cambridge: Cambridge University Press. doi:10.1017/CBO9781107415324.004.

Dilts, R., \& Bonissone, G. (1993). Skills for the future. USA: Meta Publication.

Fisher, R. (2006). Thinking skill Learning to teach in the primary school. In T. Cremin \& J. Arthur (Eds.), Learning to teach in the primary school (pp.374-388). London: Routledge.

George, D., \& Mallery, M. (2003). Using SPSS for windows step by step: a simple guide and reference. London: Pearson Education.

Gholami, M., Moghadam, P. K., Mohammadipoor, F., Tarahi, M. J., Sak, M., Toulabi, T., \& Pour, A. H. H. (2016). Comparing the effects of problem-based learning and the traditional lecture method on critical thinking skills and metacognitive awareness in nursing students in a critical care nursing course. Nurse Education Today, 45, 16-21.

Gray, M. R. (2008). The Brooklyn program: Applying NLP to addictions. In P. Tosey (Ed.), Current reasearch in NLP (Vol. 1) proceedings of 2008 conference (pp. 86-96). ANLP International CIC.

Hamza, M., \& Griffith, K. (2006). Fostering problem-solving \& creative thinking in the classroom: cultivating a creative mind. National Forum of Applied Educational Research Journal-Electronic, 19, 1-30.

Kementerian Pendidikan Malaysia. (2016). Laporan Trend Pendidikan Matematik dan Sains Antarabangsa (TIMSS) 2015. Retrieved from https://www.moe.gov.my/images/Terbitan/Rujukan-Akademik/pubfile_file_002124.pdf

King, F. J., Goodson, L., \& Rohani, F. (1998). Higher order thinking skills. Publication of the Educational Services Program, Now Known as the Center for Advancement of Learning and Assessment.

Kotera, Y., \& Sheffield, D. (2017). Disney strategy for Japanese university students' career guidance: a mixed methods pilot study. Journal of the National Institute for Career Education and Counselling, 38(1), 52-61. https://doi.org/10.20856/jnicec.3808.

Krathwohl, D. R. (2002). A revision of bloom's taxonomy: An overview. Theory Into Practice, 41(4), 212-218. https://doi.org/10.1207/s15430421tip4104_2.

Krulik, S., \& Rudnick, J. A. (1999). Innovative tasks to improve critical and creative thinking skills. In. L. Sitff (Ed.), Developing mathematical reasoning in grades $K-12$, (pp.138-145). Reston, VA: National Council of Teachers of Mathematics.

Lewis, A. (2001). Defining higher order thinking. Theory into Practice, 32(3), 131-137.

Macintosh, H. G., \& Morrisson, R. B. (1969). Objective testing. London: U of London. 
Marzano, R. J. (1993). How classroom teachers approach the teaching of thinking. Theory Into Practice, 32(3), 154-160. https://doi.org/10.1080/00405849309543591.

Mohamed, O. (2000). Prinsip psikoterapi dan pengurusan dalam kaunseling. Penerbit Universiti Putra Malaysia.

Mullis, I. V. ., Martin, M. O., Foy, P., \& Hooper, M. (2014). TIMSS 2015 international results in mathematics. TIMSS \& PIRLS International Study Center.

O’Connor, J. (2001). NLP workbook. NLP.

OECD. (2016). PISA 2015 results (Volume I): Excellence and equity in education. OECD Publishing. https://doi.org/10.1787/9789264266490-en.

Osborne, R., \& Wittrock, M. (1985). The generative learning model and its implications for science education. Studies in Science Education, 12(1), 59-87.

Piaw, C. Y. (2006). Kaedah dan Statistik Penyelidikan: Kaedah Penyelidikan Buku 1. McGRaw-Hill (Malaysia) Sdn. Bhd.

Polya, G. (1945). How to solve it: A new aspect of mathematical method. Princeton University Press.

Prayitno, B. A., Corebima, D., Susilo, H., Zubaidah, S., \& Ramli, M. (2017). Closing the science process skills gap between students with high and low level academic achievement. Journal of Baltic Science Education, 16(2), 266-277.

Robbins, A., \& Robins, A. (1986). Unlimited power: The new science of personal achievement. Unlimited power the new science of personal achievement. New York: Simon \& Schuster.

Robbins, J. K. (2011). Problem solving, reasoning, and analytical thinking in a classroom environment. The Behavior Analyst Today, 12(1), 41.

Seitova, S. M., Kozhasheva, G. O., Gavrilova, Y. N., Tasbolatova, R., Okpebaeva, G. S., Kydyrbaeva, G. T., \& Abdykarimova, A. Z. (2016). Peculiarities of using neurolinguistic programming techniques in teaching. Mathematics Edu, 11(5), 1135-1149.

Şendağ, S., \& Odabaşı, H. F. (2009). Effects of an online problem based learning course on content knowledge acquisition and critical thinking skills. Computers \& Education, 53(1), 132-141.

Storr, J., Loveday, H., Kilpatrick, C., Curran, E., \& Cooper, T. (2012). Disney, engagement, action: The infection prevention society's strategy from development to launch. Journal of Infection Prevention, 13(1), 4-10. https://doi.org/10.1177/1757177411429404.

Wallas, G. (1926). The art of thought. New York, NY: Harcourt, Brace and Company. 